\title{
Strengthening in dual-phase structured Mg-Li-Zn alloys
}

\author{
S. Kúdela Jr. ${ }^{1 *}$, P. Švec ${ }^{2}$, O. Bajana ${ }^{1}$, L. Orovčík ${ }^{1}$, P. Ranachowski ${ }^{3}$, Z. Ranachowski $^{3}$ \\ ${ }^{1}$ Institute of Materials and Machine Mechanics, Slovak Academy of Sciences, \\ Dúbravská cesta 9, 84513 Bratislava, Slovak Republic \\ ${ }^{2}$ Institute of Physics, Slovak Academy of Sciences, Dúbravská cesta 9, 84511 Bratislava, Slovak Republic \\ ${ }^{3}$ Institute of Fundamental Technological Research, Polish Academy of Sciences, \\ Pawinskiego 5B, 02-106 Warszawa, Poland
}

Received 15 February 2016, received in revised form 18 August 2016, accepted 25 August 2016

\begin{abstract}
Proof stress $R_{\mathrm{p}} 0.2$ of dual-phase $\alpha+\beta$ structured $\mathrm{Mg}-\mathrm{Li}$ and $\mathrm{Mg}-\mathrm{Li}-\mathrm{Zn}$ alloys has been inspected in terms of the strengthening contributions of $\alpha$ - and $\beta$-phases. The alloys studied with a variable fraction of $\alpha$ - and $\beta$-phases have been subjected to compression straining tests, microhardness measurements and structural analysis by EDX and XRD. Alloying with 1.5 wt.\% Zn results in the hardening of both $\alpha$ - and $\beta$-phases which however exhibit different hardening responses due to different $\mathrm{Zn}$ enrichment. The rule of the mixture has been used to interpret $R_{\mathrm{p}} 0.2$ values by taking into account the fraction of $\alpha$ - and $\beta$-phases and their strength level represented by their microhardness. Compression stress-strain curves indicate that work hardening of alloys studied depends considerably on the fraction of $\alpha$-phase and is higher for Zn-containing alloys.
\end{abstract}

K e y w or d s: Mg-Li, Mg-Li-Zn, dual-phase alloy, solution hardening, ageing, work hardening

\section{Introduction}

Alloying of magnesium with lithium is the way to produce metallic materials with an extraordinary low density nearly comparable with that of engineering plastics. For that reason, the $\mathrm{Mg}-\mathrm{Li}$ system is of both theoretical and practical interest [1]. Binary $\mathrm{Mg}-\mathrm{Li}$ phase diagram shows that Li alloying between $5.5 \mathrm{wt} . \%$ and $11.5 \mathrm{wt} . \%$ produces dual-phase $\alpha+\beta$ structured $\mathrm{Mg}$-Li alloys in which h.c.p. $\alpha$-phase coexists with b.c.c. $\beta$-phase [2]. The $\alpha$-phase is $\mathrm{Mg}(\mathrm{Li})$ solid solution and exhibits moderate strength and low formability while the $\beta$-phase is $\mathrm{Li}(\mathrm{Mg})$ solid solution possessing excellent ductility but poor creep resistance. Therefore, dual-phase $\alpha+\beta$ structure shows an interesting properties compromise combining the moderate strength of $\alpha$-phase and excellent ductility of $\beta$-phase [3]. That is why dual-phase structured $\mathrm{Mg}-\mathrm{Li}$ alloys belong to prospective engineering materials, particularly for aerospace applications.

A serious drawback of binary $\mathrm{Mg}-\mathrm{Li}$ alloys is their insufficient strength which makes them inferior as to engineering applications. Because of negligible size misfit between $\mathrm{Mg}$ and $\mathrm{Li}$ atoms practically no solid solution strengthening occurs in binary $\mathrm{Mg}-\mathrm{Li}$ alloys. Moreover, the absence of intermetallics in Mg-Li system eliminates the capability for precipitation hardening. For that reason, the Mg-Li alloys are alloyed with third element $\mathrm{X}$ (usually $\mathrm{Al}, \mathrm{Zn}$ ) to initiate the formation of LiX precipitates at ageing [4]. Nevertheless, the maximum hardening effect is reached through metastable $\mathrm{MgLi}_{2} \mathrm{X}$ product (Guinier-Preston type phase) which precedes the formation of stable LiX phase. Thus, a suitable hardening regime is the long-term room temperature ageing (natural ageing) producing only $\mathrm{MgLi}_{2} \mathrm{X}$ without the risk of overageing $[5]$.

As for the dual-phase Mg-Li-X alloys, the element $\mathrm{X}$ is dissolved in both $\alpha$ and $\beta$ phases so that the hardening occurs in each of these constituents [6]. This phenomenon is poorly understood till now, so it is worthy of deeper study. This is a topic of the present work which is focused on the relation between the proof stress $R_{\mathrm{p}} 0.2$ of dual-phase $\mathrm{Mg}$-Li type al-

*Corresponding author: tel.: +421 2 32401029; e-mail address: ummskudm@savba.sk 
Ta ble 1. Actual chemical composition of $\mathrm{Mg}-\mathrm{Li}$ and $\mathrm{Mg}$ -Li-Zn alloys studied and the fraction of $\alpha$-phase

\begin{tabular}{clc}
\hline Alloy & Composition (wt.\%) & $\alpha$-phase (vol.\%) \\
\hline A & Mg-6.24\%Li & 74.5 \\
B & Mg- $8.92 \% \mathrm{Li}$ & 33.2 \\
C & Mg-9.98\%Li & 24.0 \\
D & Mg-6.12\%Li-1.42\%Zn & 78.9 \\
E & Mg-8.64\%Li-1.62\%Zn & 36.6 \\
F & Mg-10.3\%Li-1.63\%Zn & 18.4 \\
\hline
\end{tabular}

loys and the strengthening contribution of $\alpha$ - and $\beta$-phases represented by their microhardness. For that purpose, there have been prepared $\mathrm{Mg}$-Li alloys with variable $\mathrm{Li}$ alloying thus creating the dual-phase $\alpha+\beta$ structure with different fractions of $\alpha$ - and $\beta$-phases. A similar set of dual-phase $\mathrm{Mg}-\mathrm{Li}-\mathrm{Zn}$ alloys has also been fabricated in which $1.5 \mathrm{wt} . \% \mathrm{Zn}$ should generate the solution hardening. The proof stress $R_{\mathrm{p}} 0.2$ as determined by compression straining test has been inspected as a function of volume fraction of $\alpha$ - and $\beta$-phases and their microhardness. Before being compression strained, each of alloy samples was examined in terms of the microstructure, microhardness, and $\mathrm{XRD}$ analysis. The strained samples were chemically analysed to determine actual chemical composition.

\section{Experiment}

\subsection{Alloys fabrication}

The alloys with nominal compositions of $\mathrm{Mg}-6 \mathrm{Li}$ (A), Mg-9Li (B), Mg-10Li (C), Mg-6Li-1.5Zn (D), Mg-9Li-1.5Zn (E) and Mg-10Li-1.5Zn (F) were prepared by melting of pure magnesium, lithium, and zinc metals (purities of 99.9, 99.0 and $99.9 \%$, respectively) in a mild-steel crucible followed with the casting into a cylindric steel mould. The actual alloy compositions as determined by atomic emission spectral analysis are presented in Table 1 . Both melting and casting operations were conducted in the same chamber under an argon pressure of $0.5 \mathrm{MPa}$ after the previous evacuation. The alloys prepared were stored at ambient temperature under argon atmosphere for about 1 month to be naturally aged.

\subsection{Compression tests}

Cylindric samples ( $\varnothing 4 \mathrm{~mm}$, length $8 \mathrm{~mm}$ ) were prepared by turning operations from naturally aged A F alloys. The samples were then compression strained in ZWICK Z100 apparatus at the room temperature to determine the yield point $R_{\mathrm{p}} 0.2$ from engineering stress-strain curves.

\subsection{Microhardness measurements}

Microhardness measurements were conducted on metallographically prepared alloy surfaces using the FM-1E microhardness tester equipped with a Vickers indenter by imposing a load of $5 \mathrm{gf}$ for $10 \mathrm{~s}$. The microhardness data of each of $\alpha$ - and $\beta$-phases were taken from twenty randomly selected sites. The microhardness $\mathrm{HV}$ was determined as an arithmetic mean value of measured data.

\subsection{Microstructural observations}

The structure of alloys studied was examined using the scanning electron microscope (SEM, Jeol JSM 7600F) equipped with Retractable Backscattered Electron Detector (RBEI). Before being SEM inspected and EDX analysed, the specimens were metallographically polished to a mirror-like finish without etching. Energy dispersive spectrometer operating at $15 \mathrm{kV}$ was used for elemental analysis.

\subsection{XRD analysis}

X-ray diffraction (XRD) records were acquired from metallographically polished sample surfaces using $\mathrm{CuK} \alpha$ radiation by means of Bruker D 8 diffractometer.

\section{Results}

\subsection{Microstructural observations}

According to $\mathrm{Mg}$-Li phase diagram, binary $\mathrm{Mg}-\mathrm{Li}$ alloys containing 5.7-10.3 wt.\% Li have a dual-phase structure consisting of a mixture of $\alpha$ - and $\beta$-phases in which the fraction of $\alpha$-phase decreases with increasing Li content [7]. Effect of Li content on the morphology and distribution of $\alpha$ - and $\beta$-phases in A, B, and $\mathrm{C}$ alloys is shown in Figs. 1a-c. Hypoeutectic alloy $\mathrm{A}$ containing $6.2 \mathrm{wt} . \% \mathrm{Li}$ (eutectic point at $8.0 \mathrm{wt} . \% \mathrm{Li}$ ) consists of large regions of mostly continuous $\alpha$-phase and irregularly distributed minor $\beta$-phase (Fig. 1a). The structure of hyper-eutectic alloy B with $8.9 \mathrm{wt} . \%$ Li comprises elongated blocks of $\alpha$-phase surrounded with continuous $\beta$-matrix (Fig. 1b). In hyper-eutectic alloy $\mathrm{C}$ with about $10 \mathrm{wt} . \% \mathrm{Li}$, minor $\alpha$-phase is crumbled into small isolated particles embedded into $\beta$-matrix (Fig. 1c). Besides $\alpha$-phase crystallizing from the melt, there have also been found in alloys $\mathrm{B}$ and $\mathrm{C}$ within $\beta$-phase fine needle-like $\alpha$-precipitates (Fig. 2). They might be the Widmanstätten type precipitates precipitating in solid $\beta$-phase due to the drop in $\mathrm{Mg}$ solubility on the cooling [8]. Volume fractions of primary $\alpha$-phase (without precipitates of secondary $\alpha$-phase) in alloys $\mathrm{A}, \mathrm{B}$, and $\mathrm{C}$ as determined by the 

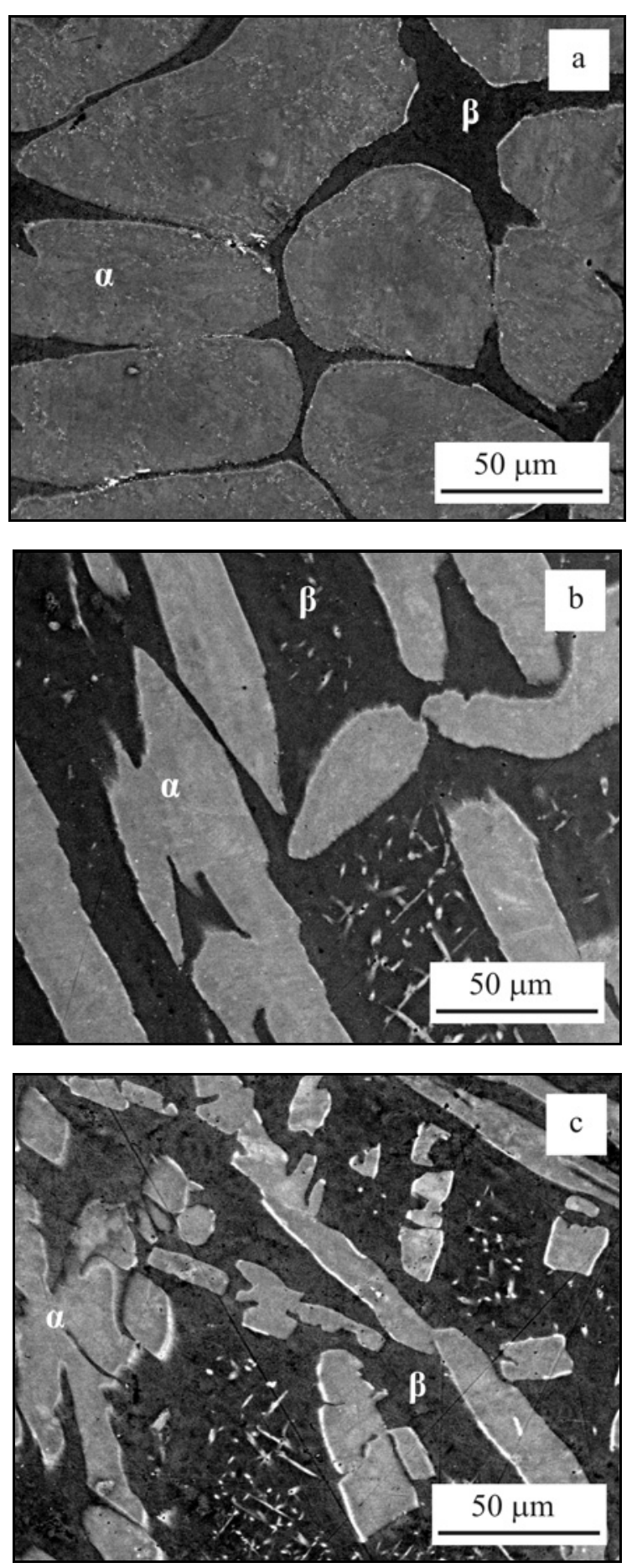

Fig. 1. SEM images in back scattering electron (BSE) mode of the microstructure of samples A, B, and C demonstrating the effect of $\mathrm{Li}$ alloying on the morphology and fraction of $\alpha$-phase (light). There are visible needle-like secondary $\alpha$-phase precipitates inside the $\beta$-phase (dark) in samples B and C.

linear intercept method are presented in Table 1.

The section of equilibrium Mg-Li-Zn phase diagram for constant 1-2 wt.\% Zn differs negligibly from

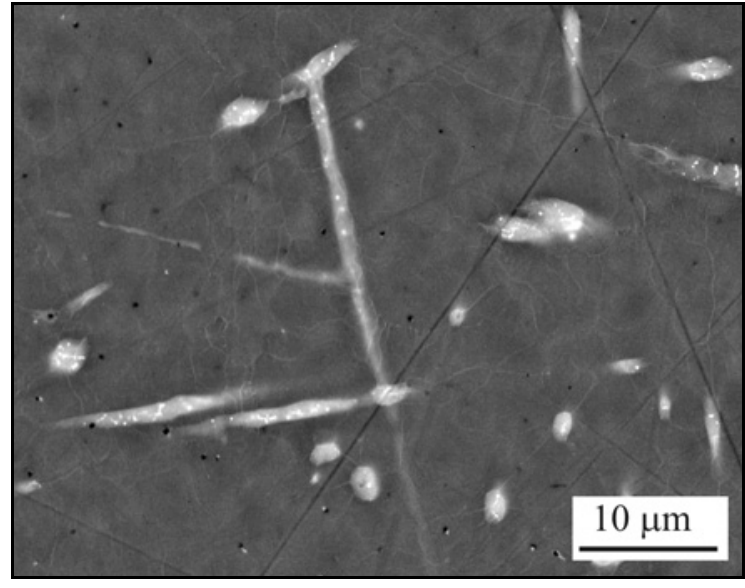

Fig. 2. SEM image in BSE mode of needle-like precipitates of secondary $\alpha$-phase. The bright spots are indicative of Zn-enriched sites.

that of binary $\mathrm{Mg}-\mathrm{Li}$ one, i. e. it consists of $\alpha, \alpha+\beta$ and $\beta$ solid solution areas containing $\mathrm{Zn}$ solute [9]. That is why the morphological features of $\alpha$-phase in 1.5 wt. \% $\mathrm{Zn}$ alloyed D $-\mathrm{F}$ alloys are very similar to those observed in binary A $-\mathrm{C}$ alloys including the occurrence of secondary $\alpha$-precipitates in alloys $\mathrm{E}$ and F. Fractions of primary $\alpha$-phase in alloys $\mathrm{D}-\mathrm{F}$ are presented in Table 1.

EDX analysis has been used to investigate $\mathrm{Zn}$ distribution over $\alpha$ - and $\beta$-phases in $\mathrm{D}, \mathrm{E}$, and $\mathrm{F}$ alloys wherein EDX mapping suggests that $\mathrm{Zn}$ is distributed within both $\alpha$ and $\beta$ regions significantly, however, more in $\beta$-phase (Fig. 3). Nevertheless, proper quantitative EDX inspection is impossible as Li cannot principally be detected by this technique. Provided that the solution limit of $\mathrm{Li}$ in $\alpha$ - and $\beta$-phases (5.7 and $10.3 \mathrm{wt} . \% \mathrm{Li}$, respectively) has been reached there has been estimated from EDX data the concentration ratio $\mathrm{Zn}(\beta) / \mathrm{Zn}(\alpha)$ for alloys $\mathrm{D}, \mathrm{E}$, and $\mathrm{F}$ obtaining the values of $3.7,2.9$, and 2.7 , respectively. Thus, the concentration of $\mathrm{Zn}$ in $\beta$-phase appears to be roughly 2.5 4 times higher than that in $\alpha$-phase. This also suggests that $\alpha$-phase crystallizing from hypo-eutectic $\mathrm{Mg}-\mathrm{Li}$ -Zn melt is less Zn-enriched than that formed by crystallization in the hyper-eutectic region. The needles of secondary $\alpha$-phase in alloys $\mathrm{E}$ and $\mathrm{F}$ are not suitable for quantitative EDX analysis since they are too fine so that obtained analytical data could be affected with surrounding $\beta$-phase. Nevertheless, BSE image of $\alpha$-needles in Fig. 2 reveals that $\mathrm{Zn}$ is non-uniformly distributed within them (bright spots).

\subsection{XRD analysis}

XRD records have been acquired from $\mathrm{A}-\mathrm{F}$ alloys to characterize their phase composition. The comparison of XRD patterns in Fig. 4 shows that in 

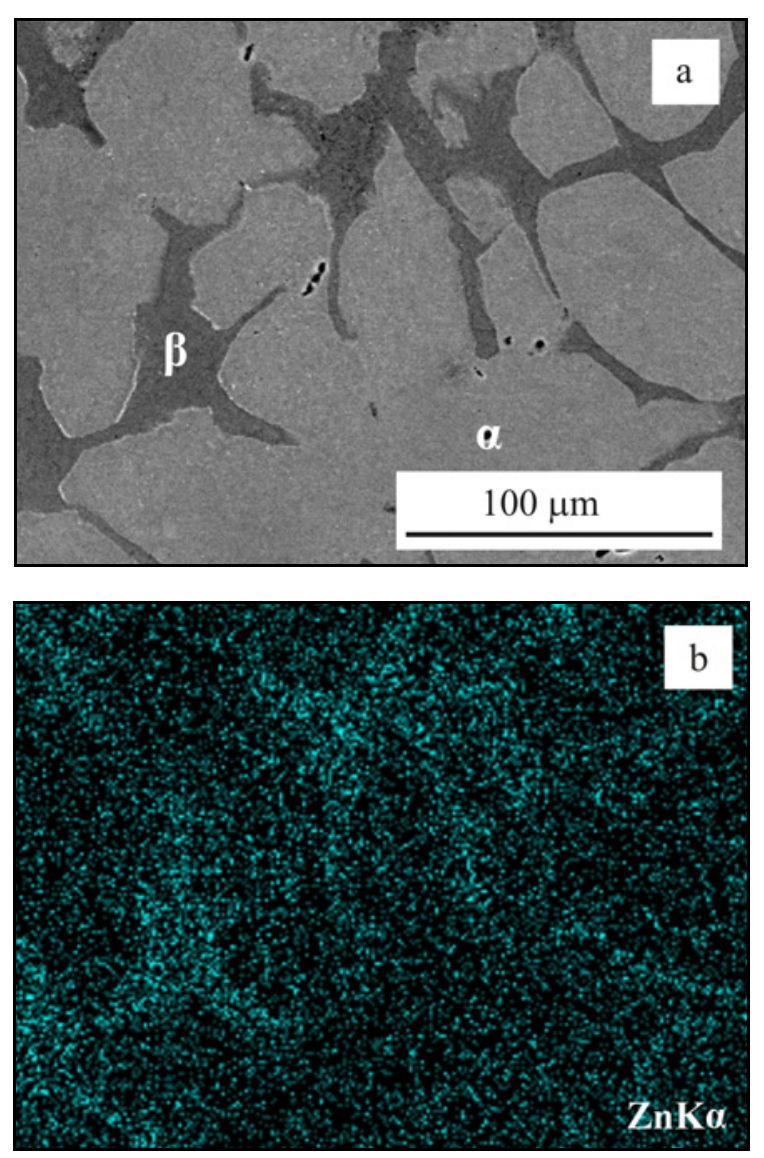

Fig. 3. Electron image (a) and EDX mapping of $\mathrm{ZnK} \alpha$ radiation of sample $\mathrm{E}(\mathrm{b})$.

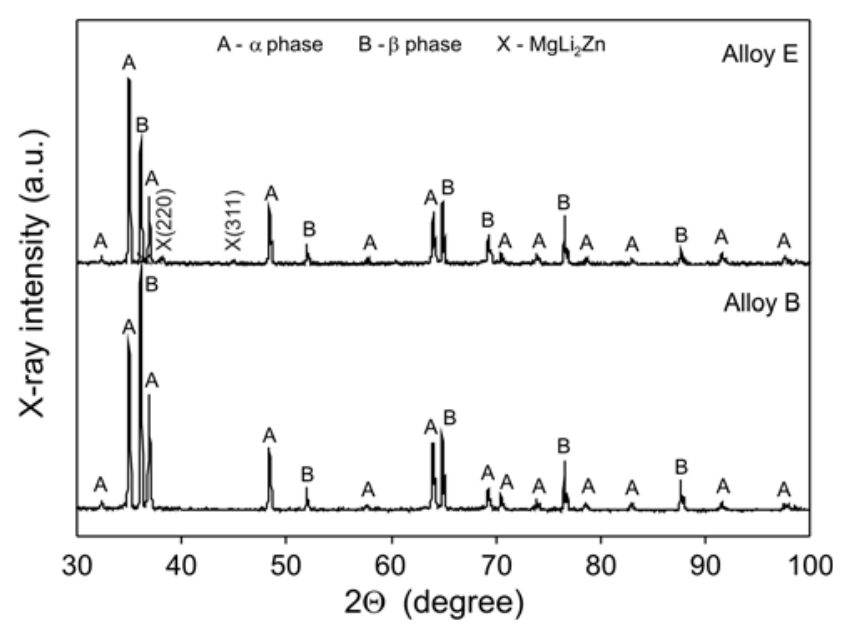

Fig. 4. XRD records of samples $\mathrm{B}$ and $\mathrm{E}$ evidencing the presence of b.c.c. $\mathrm{MgLi}_{2} \mathrm{Zn}$ phase in sample $\mathrm{E}$ through (311) and (220) peaks.

present $\mathrm{Mg}-\mathrm{Li}-\mathrm{Zn}$ alloys besides h.c.p. $\alpha$-phase and b.c.c. $\beta$-phase there also occurs metastable $\theta^{\prime}$ product $\left(\mathrm{MgLi}_{2} \mathrm{Zn}\right)$ that has been identified through (311)

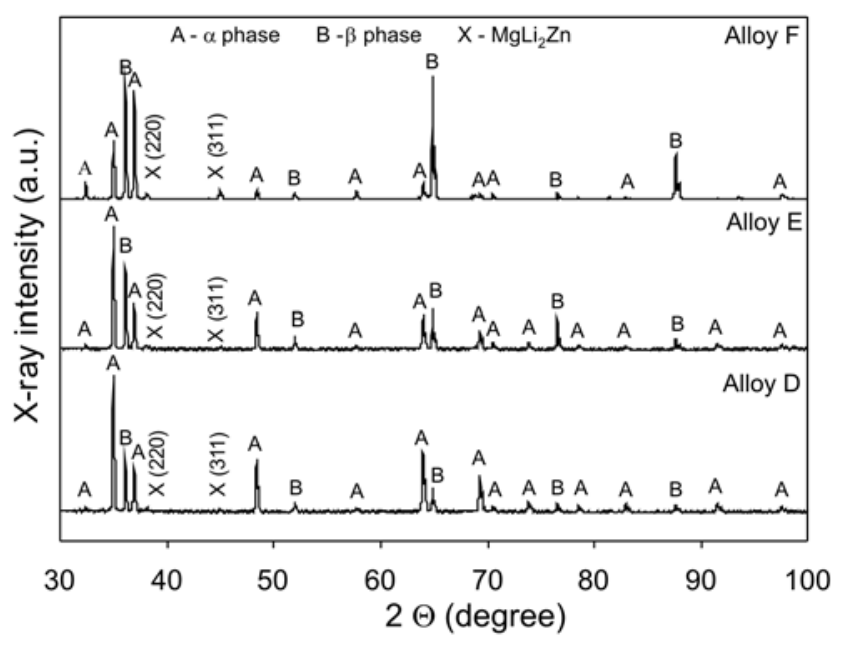

Fig. 5. XRD records of samples $\mathrm{D}, \mathrm{E}$, and $\mathrm{F}$ showing the development of (311) and (220) peaks of $\mathrm{MgLi}_{2} \mathrm{Zn}$ phase with the increase in Li alloying. The development of $\alpha$-phase related peaks at about $32^{\circ}$ can be attributed to secondary $\alpha$-phase precipitates.

and (220) peaks. Intermediate $\theta^{\prime}$ product with b.c.c. crystal symmetry has apparently been formed during long-term natural ageing. Stable $\mathrm{ZnLi}$ phase has not been detected as it should appear only after ageing above $75^{\circ} \mathrm{C}[10]$. Phase $\theta^{\prime}$ is structurally coherent with b.c.c. $\beta$-phase so it possesses great strengthening potential due to the lattice distortion (analogy of G-P. zones). Thus, metastable $\theta^{\prime}$-phase precipitates inside $\mathrm{Zn}$ solute hardened $\beta$-phase so that both solid solution strengthening and age hardening should operate in alloys $\mathrm{D}-\mathrm{F}$. XRD patterns taken from alloys $\mathrm{D}-\mathrm{F}$ (Fig. 5) indicate that $\theta^{\prime}$ related peaks grow simultaneously with the peaks of $\beta$-phase as Li alloying increases thus suggesting that $\beta$-phase regions are favourable sites for precipitation of $\theta^{\prime}$-phase. Accordingly, stronger $\beta$-phase related peaks are simply due to greater fraction of this phase. In a similar way, it can be explained rather a controversial occurrence of $\alpha$-phase related peaks positioned at $\sim 32^{\circ}$ and $\sim 37^{\circ}$ that have been developed simultaneously with the peaks of $\beta$-phase. It is thought that these peaks belong to secondary $\alpha$-phase crystallizing inside the regions of $\beta$-phase which are enlarged with an increase in $\mathrm{Li}$ alloying.

\subsection{Microhardness and deformation tests}

The microhardness data of $\alpha$ - and $\beta$-constituents in $\mathrm{A}-\mathrm{F}$ alloys are presented in Table 2 . As for binary $\mathrm{Mg}-\mathrm{Li}$ alloys $\mathrm{A}-\mathrm{C}$, the microhardness values of $\alpha$ - and $\beta$-phases differ only slightly from each other although $\alpha$-phase is still slightly tougher. It is also seen that different $\mathrm{Li}$ content results in insignificant variations in microhardness of individual $\alpha$ - and $\beta$ - phases. As 
Table 2. The data on proof stress $R_{\mathrm{p}} 0.2$, microhardness $\mathrm{HV}(5)$ and slope of straining curves $\Delta \sigma / \Delta \varepsilon$ in plastic deformation region of present $\mathrm{Mg}-\mathrm{Li}$ and $\mathrm{Mg}-\mathrm{Li}-\mathrm{Zn}$ alloys

\begin{tabular}{ccccc}
\hline \multirow{4}{*}{ Alloy } & $\begin{array}{r}R_{\mathrm{p}} 0.2 \\
(\mathrm{MPa})\end{array}$ & $\alpha$ & $\beta$ & \begin{tabular}{c}
$\mathrm{HV}(\mathrm{MPa})$ \\
\cline { 3 - 4 }$(\mathrm{MPa})$
\end{tabular} \\
\hline $\mathrm{A}$ & 91.8 & 56.1 & 51.1 & 5.4 \\
$\mathrm{~B}$ & 89.6 & 55.6 & 54.7 & 4.2 \\
$\mathrm{C}$ & 85.1 & 56.1 & 53.8 & 4.0 \\
$\mathrm{D}$ & 93.6 & 58.9 & 63.5 & 6.8 \\
$\mathrm{E}$ & 108.2 & 64.1 & 62.4 & 4.7 \\
$\mathrm{~F}$ & 104.1 & 68.3 & 64.2 & 4.1 \\
\hline
\end{tabular}

expected, the microhardness values of $\alpha$ - and $\beta$-phases in $\mathrm{Zn}$ alloyed samples $\mathrm{D}-\mathrm{F}$ are considerably higher than those in alloys $\mathrm{A}-\mathrm{C}$ wherein this difference is greater for hypereutectic alloys containing more Li. It is also seen that $\alpha$ - and $\beta$-phases in alloys $\mathrm{D}-\mathrm{F}$ show different hardening responses: the microhardness of $\alpha$-phase rises gradually as $\mathrm{Li}$ alloying increases while $\beta$-phase is hardened immediately exhibiting quite small microhardness variations.

Proof stress $R_{\mathrm{p}} 0.2$ is used here as the criterion characterizing overall strength level of alloys studied. The compression stress-strain diagrams of alloys $\mathrm{A}-\mathrm{F}$ are shown in Figs. $6 \mathrm{a}-\mathrm{c}$ and corresponding $R_{\mathrm{p}} 0.2$ values determined in usual way are presented in Table 2 . It is seen that $R_{\mathrm{p}} 0.2$ values of binary $\mathrm{Mg}-\mathrm{Li}$ alloys $\mathrm{A}-\mathrm{C}$ vary within the quite narrow range of 85-92 MPa showing slight softening tendency with an increase in $\mathrm{Li}$ content. $\mathrm{Zn}$ addition (alloys D - F) significantly increases $R_{\mathrm{p}} 0.2$ values particularly for alloys $\mathrm{E}$ and $\mathrm{F}$ reaching the maximum of $108 \mathrm{MPa}$ for alloy $\mathrm{E}$ followed with small softening observed in alloy F. Simply saying, in alloys $\mathrm{A}-\mathrm{C}$ growing Li content results in their softening while in alloys D $-\mathrm{F}$ an opposite tendency can be observed.

The comparison of straining curves in Figs. 6a-c suggests that alloys A - F show different work hardening behaviour. Present stress-strain curves $\sigma-\varepsilon$ are of usual shape exhibiting nearly linear section immediately after the plastic deformation onset. Experimental data $\sigma-\varepsilon$ have been treated by the linear regression over the straining section of $15-30 \%$ and the slope $(\Delta \sigma / \Delta \varepsilon)$ of fitted lines is taken as the work hardening tendency criterion. The results are collected in Table 2 offering two observations: (a) $\Delta \sigma / \Delta \varepsilon$ rises as the fraction of $\alpha$-phase increases and, (b) $\Delta \sigma / \Delta \varepsilon$ is higher for Zn-containing alloys particularly for those with a large fraction of $\alpha$-phase. In other words, the work hardening tendency is lowered with increase in Li content for both $\mathrm{A}-\mathrm{C}$ and $\mathrm{D}-\mathrm{F}$ alloy sets. It is interesting to note that $\alpha$-phase based alloy $\mathrm{D}$ shows the greatest work hardening tendency while
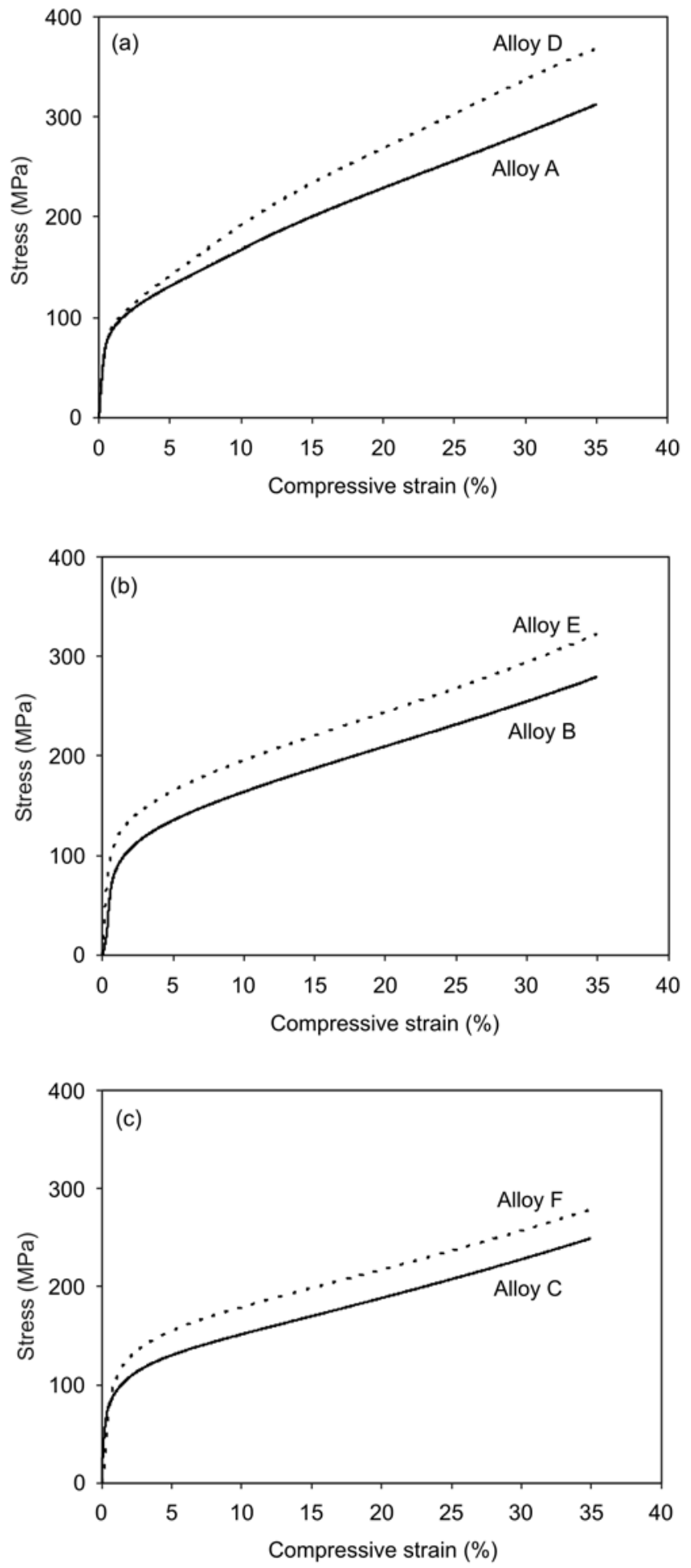

Fig. 6. Compression stress-strain curves of samples A and $\mathrm{E}(\mathrm{a}), \mathrm{B}$ and $\mathrm{E}$ (b), C and $\mathrm{E}$ (c) demonstrating the effect of $\mathrm{Zn}$ alloying and a different fraction of $\alpha$-phase on the work hardening.

its strengthening due to $\mathrm{Zn}$ alloying is the smallest (Fig. 4a). 


\section{Discussion}

The structure of present dual-phase $\mathrm{Mg}-\mathrm{Li}$ and $\mathrm{Mg}$ -Li-Zn alloys generally consists of continuous major phase in which the minor phase is discontinuously distributed. The most simple approach enabling to express the mean stress $\sigma$ needed for overall straining $\varepsilon$ of dual-phase alloy consisting of $\alpha$ - and $\beta$-phases is the rule of mixture (ROM):

$$
\sigma=X_{\alpha} \sigma_{\alpha}+X_{\beta} \sigma_{\beta}
$$

where $\sigma_{\alpha}$ and $\sigma_{\beta}$ are the stresses in $\alpha$ - and $\beta$-phases per volume unit and $X_{\alpha}$ and $X_{\beta}$ are the phase volume fractions. Equation (1) can be rewritten as:

$$
\sigma=\sigma_{\alpha}+X_{\beta}\left(\sigma_{\beta}-\sigma_{\alpha}\right)
$$

to characterize the strengthening of continuous $\alpha$-matrix with minor $\beta$-phase, or item for continuous $\beta$-matrix and minor $\alpha$-phase:

$$
\sigma=\sigma_{\beta}+X_{\alpha}\left(\sigma_{\alpha}-\sigma_{\beta}\right)
$$

Thus, the strength of dual-phase alloy can be expressed as the sum of two terms: (i) strength of the matrix phase, and (ii) strengthening increment from the discontinuous minor phase. The latter term is governed with the volume fraction of minor phase and the phase strength difference.

In the present study, ROM Eqs. (2) and (3) have been applied to interpret experimental $R_{\mathrm{p}} 0.2$ values of alloys studied relating to the strengthening contribution of individual phases represented by their microhardness. The microhardness can be considered a reliable strength level parameter as a linear relationship between the microhardness and the proof stress has experimentally been confirmed $[11,12]$.

The microhardness data of binary $\mathrm{Mg}-\mathrm{Li}$ alloys $\mathrm{A}$, $\mathrm{B}$, and $\mathrm{C}$ indicate that $\sigma_{\alpha}>\sigma_{\beta}$. As a result, the $\alpha$-matrix based alloy A should be softened by the presence of $\beta$-phase as the second term in Eq. (1) is negative. On the other hand, $\beta$-matrix based alloys $\mathrm{B}$ and $\mathrm{C}$ should be strengthened with $\alpha$-phase as the second term in Eq. (2) is positive. This strengthening is however eliminated with lower $X_{\alpha}$ resulting from higher Li alloying. In other words, an experimentally observed drop in $R_{\mathrm{p}} 0.2$ with rising Li content in alloys $\mathrm{A}-\mathrm{C}$ should be attributed to rising percentage of softer $\beta$-phase at the expense of stronger $\alpha$-phase.

Zn-strengthened alloys D, E, and F behave rather differently. Alloy D is composed of $\alpha$-matrix and minor $\beta$-phase wherein the microhardness data indicate that $\sigma_{\beta}>\sigma_{\alpha}$. Hence, according to the Eq. (2), the $\beta$-phase should generate the strengthening which however is rather small as the fraction of $\beta$-phase is low. As a result, the alloys $\mathrm{A}$ and $\mathrm{D}$ differ in their $R_{\mathrm{p}} 0.2$ values only slightly. On the other hand, the Eq. (3) implies that $\beta$-matrix based alloys $\mathrm{E}$ and $\mathrm{F}$ should be strengthened with $\alpha$-phase because $\sigma_{\alpha}>\sigma_{\beta}$ as follows from the microhardness data. This strengthening is however gradually reduced by vanishing of stronger $\alpha$-phase due to higher Li alloying, although this softening effect can partly be eliminated with an increase in difference $\left(\sigma_{\alpha}-\sigma_{\beta}\right)$. Hence, rather complex hardening-softening interplay takes place here. As a result, alloy E shows slightly higher $R_{\mathrm{p}} 0.2$ value than alloy $\mathrm{F}$ wherein both of these $\beta$-matrix based alloys are considerably stronger than $\alpha$-matrix based alloy D.

It is important to note that deformation behaviour of dual-phase $\alpha+\beta$ alloys depends besides the volume fraction and the strength of individual phases also on their topology. If e.g. strong $\alpha$-matrix is continuous and soft $\beta$-phase is discontinuous then $\varepsilon_{\alpha}=\varepsilon_{\beta}=\varepsilon$, i.e. overall alloy straining is equal to that of stronger $\alpha$-phase. On the other hand, if soft $\beta$-phase is a continuous matrix and strong $\alpha$-phase are isolated particles major part of deformation occurs in $\beta$-phase so that $\varepsilon_{\beta}<\varepsilon[13]$. These considerations suggest that overall straining behaviour of dual-phase alloys can be largely influenced by straining properties of the matrix phase.

As already mentioned, straining curves of alloys $\mathrm{A}-\mathrm{F}$ indicate that their work hardening increases with the fraction of $\alpha$-phase and is intensified with $\mathrm{Zn}$ alloying (Figs. 6a-c). The work hardening of metallic alloys is usually interpreted as the hardening-softening processes competition. The hardening is generated by the multiplication of dislocations at obstacles or the forest dislocations while the softening is usually connected with the cross slip and/or climb of dislocations $[14,15]$. The dislocations obstacles in alloys $\mathrm{D}-\mathrm{F}$ are apparently $\mathrm{Zn}$ solute atoms and/or $\mathrm{MgLi}_{2} \mathrm{Zn}$ precipitates. At the same time, the softening resulting from dislocation cross-slip and/or the dislocation climb can also be active.

The latter two processes are typical for elevated temperatures, nevertheless, in b.c.c. $\beta$-phase they may operate even at the room temperature due to extraordinary high Li diffusivity. This is demonstrated by pronounced room temperature creep observed in $\beta$-phase based Mg-Li alloys [16]. Besides, acoustic emission signals taken from compression strained $\beta$-phase based $\mathrm{Mg}-\mathrm{Li}$ and $\mathrm{Mg}-\mathrm{Li}-\mathrm{Al}$ alloys provided an evidence of the non-collective dislocation movement, i.e. the dislocation cross-slip and/or climb [17]. Note that similar diffusion-assisted softening of h.c.p. $\alpha$-phase at the room temperature can hardly be initiated because of $\sim 10^{3}$ times slowlier Li diffusion compared to $\beta$-phase [18]. As a result, the work hardening at room temperature strained dual-phase $\mathrm{Mg}$-Li alloys should be largely controlled with the fraction of $\alpha$-phase.

There has also been observed that the presence of $\mathrm{Zn}$ solute results in significant increase in the work 
hardening particularly for $\alpha$-phase based alloy F. A possible reason for that might be the drop in stacking fault energy in h.c.p. $\alpha$-phase due to $\mathrm{Zn}$ addition which should facilitate the split of dislocations and consequently initiate the drop in climbing ability [19]. A similar increase in work hardening due to $\mathrm{Zn}$ addition has also been observed in plastically strained $\mathrm{Mg}-\mathrm{Zn}$ alloys also having h.c.p. structure [20]. In contrast to $\mathrm{Mg}-\mathrm{Zn}$ alloys, the work hardening in dualphase $\mathrm{Mg}-\mathrm{Li}-\mathrm{Zn}$ alloys can largely be affected by activation of pyramidal slip planes in h.c.p. $\alpha$-phase beside the basal ones [21]. The topic of plastic deformation of $\mathrm{Mg}-\mathrm{Li}-\mathrm{Zn}$ alloys is however beyond the scope of the present paper.

\section{Conclusions}

There have been prepared dual-phase structured $\mathrm{Mg}-\mathrm{Li}$ and $\mathrm{Mg}-\mathrm{Li}-\mathrm{Zn}$ alloys with variable fractions of $\alpha$ - and $\beta$-phases due to different Li alloying. The addition of $1.5 \mathrm{wt} . \% \mathrm{Zn}$ initiates the hardening of individual phases. The alloys have been examined by compression straining test, microhardness, XRD, and EDX analysis. The following conclusions are drawn:

1. $\mathrm{Mg}-\mathrm{Li}-\mathrm{Zn}$ alloys show greater proof stress $R_{\mathrm{p}} 0.2$ than Mg-Li ones due to solution hardening and hardening through $\mathrm{MgLi}_{2} \mathrm{Zn}$ phase. Strengthening from $\mathrm{Zn}$ alloying is greater in hyper-eutectic alloys with a larger fraction of $\beta$-phase.

2. Microhardness data indicate that $\mathrm{Zn}$ alloying results in hardening of both $\alpha$ and $\beta$ constituents that however exhibit different hardening responses due to different $\mathrm{Zn}$ enrichment.

3. $R_{\mathrm{p}} 0.2$ values can be interpreted using the rule of the mixture by taking into account the fraction of $\alpha$ - and $\beta$-phases and their microhardness.

4. The work hardening increases with the fraction of $\alpha$-phase and is greater for Zn alloyed samples.

\section{Acknowledgements}

Grant Agency of the Slovak Republic VEGA is acknowledged for supporting this work (Project No. 2/0186/ 14). Support of the APVV-14-0934 project is also acknowledged.

\section{References}

[1] Wu, R., Yan, Y., Wang, G., Murr, L. E., Han, W., Zhang, Z., Zhang, M.: Int. Mater. Rev., 60, 2015, p. 65. doi:10.1179/1743280414Y.0000000044
[2] Nayeb-Hashemi, A. A., Clark, J. B., Pelton, A. B.: Bulletin of Alloy Phase Diagrams, 5, 1984, p. 365.

[3] Haferkamp, H., Jaschik, C., Juchmann, P., Kaese, V., Niemeyer, M., Tai, P.: Materialswissenschaft und Werkstofftechnik, 32, 2001, p. 25. doi:10.1002/1521-4052(200101)32:1<25::AIDMAWE25 $>3.0 . \mathrm{CO} ; 2-\mathrm{J}$

[4] Jackson, J. H., Frost, P. D., Loonam, A. C., Eastwood, L. W., Lorig, C. H.: Transactions AIME, 185, 1949, p. 149.

[5] McDonald, J. C.: Journal of the Institute of Metals, 97, 1969, p. 353.

[6] Kim, D. H., Han, Y. S., Lee, H. I., Cantor, B.: Scripta Met. Mater., 31, 1994, p. 819. doi:10.1016/0956-716X(94)90485-5

[7] Kim, Y. W., Kim, D. H., Lee, H. I., Hong, C. P.: Scripta Mater., 38, 1998, p. 923. doi:10.1016/S1359-6462(97)00573-3

[8] Yamamoto, A., Ashida, T., Kouta, Y., Kim, K. B., Fukumoto, S., Tsubakino, H.: Mater. Trans., 44, 2003, p. 619. doi:10.2320/matertrans.44.619

[9] Schemme, K.: Development of Super-Light Magnesium Materials. Düsseldorf, VDI-Verlag 1993. (in German)

[10] Drits, M. E., Yelkin, F. M., Gurev, I. I., Bondarev, B. I., Trokhova, V. F., Sergievskaya, A. D., Osokina, T. N.: Magnesium-Lithium Alloys. Moscow, Metallurgija 1980. (in Russian)

[11] Zhang, P., Li, S. X., Zhang, Z. F.: Mater Sci. Eng. A, 529, 2011, p. 62. doi:10.1016/j.msea.2011.08.061

[12] Cáceres, C. H., Griffiths, J. R., Pakdel, A. R., Davidson, C. J.: Mater. Sci. Eng. A, 402, 2005, p. 258. doi:10.1016/j.msea.2005.04.042

[13] Puškár, A.: Microplasticity and Failure of Metallic Materials. Amsterdam, Elsevier 1988.

[14] Lukáč, P., Trojanová, Z.: Mater Sci. Eng. A, 462, 2007, p. 23. doi:10.1016/j.msea.2006.01.170

[15] Cáceres, C. H., Blake, A. H.: Mater Sci. Eng. A, 462, 2007, p. 193. doi:10.1016/j.msea.2005.12.113

[16] Clyne, T. W., Withers, P. J.: An Introduction to Metal Matrix Composites. Cambridge, Cambridge University Press 1993. doi:10.1017/CBO9780511623080

[17] Jasienski, Z., Kúdela, S., Litwora, A., Pawelek, A., Piatkowski, A.: Molecular \& Quantum Acoustics, 23, 2002, p. 351.

[18] Iwadate, Y., Lassouani, M., Lantelme, F., Chmela, M.: Journal of Applied Electrochemistry, 17, 1987, p. 385. doi:10.1007/BF01023304

[19] Máthis, K., Trojanová, Z., Lukáč, P., Cáceres, C. H., Lendvai, J.: J. Alloys Compd., 378, 2004, p. 176. doi:10.1016/j.jallcom.2003.10.098

[20] Máthis, K.: Study of Plastic Deformation of Magnesium Alloys. [Ph.D. Thesis]. Prague, Charles University 2000.

[21] Kamado, S., Kojima, J.: Metallurgical Science \& Technology, 16, 1998, p. 45. 